University of Wollongong

Research Online

Faculty of Engineering and Information

Faculty of Engineering and Information

Sciences - Papers: Part A

Sciences

$1-1-2016$

\title{
Addressing misconceptions about engineering through student-industry interaction in a video-augmented 3D immersive virtual world
}

Sasha Nikolic

University of Wollongong, sasha@uow.edu.au

Thomas Goldfinch

University of Wollongong, tomgold@uow.edu.au

Mark Jian Wei Lee

Charles Sturt University, mjwl598@uow.edu.au

Christian H. Ritz

University of Wollongong, critz@uow.edu.au

Follow this and additional works at: https://ro.uow.edu.au/eispapers

Part of the Engineering Commons, and the Science and Technology Studies Commons

Research Online is the open access institutional repository for the University of Wollongong. For further information contact the UOW Library: research-pubs@uow.edu.au 


\title{
Addressing misconceptions about engineering through student-industry interaction in a video-augmented 3D immersive virtual world
}

\begin{abstract}
A key goal of engineering education is to ensure students are adequately prepared to enter professional practice. Unfortunately, students have been found to bring to university significant misconceptions about the types of work engineers perform, which can have an adverse impact on their readiness to fully appreciate and benefit from course activities. This paper presents a case study of how iSee, a collaborative online platform that allows for video conferencing within a three-dimensional immersive virtual world, was used to host a careers fair event in which students learned about the engineering profession and about the various engineering majors available to them by networking and interacting with alumni and faculty. The planning and execution of the event are described, along with the pedagogical, technological, and logistical considerations and design decisions that were made. Preliminary results suggest the activity, despite being low cost, was effective at generating productive dialogue between participants that focused on what students could expect upon graduating in terms of employment prospects, as well as the academic pathways and other learning opportunities they needed to pursue to realize their goals.
\end{abstract}

\section{Keywords}

engineering, about, misconceptions, addressing, interaction, immersive, video-augmented, virtual, 3d, world, student-industry

\section{Disciplines \\ Engineering | Science and Technology Studies}

\section{Publication Details}

S. Nikolic, T. Goldfinch, M. J.W. Lee \& C. H. Ritz, "Addressing misconceptions about engineering through student-industry interaction in a video-augmented 3D immersive virtual world," in IEEE Frontiers in Education Conference (FIE), 2016, pp. 1-6. 


\section{Addressing Misconceptions About Engineering Through Student-Industry Interaction in a Video-Augmented 3D Immersive Virtual World}

\author{
Sasha Nikolic \\ Engineering and Information Sciences \\ University of Wollongong \\ Wollongong, NSW, Australia \\ sasha@uow.edu.au \\ Tom Goldfinch \\ Engineering and Information Sciences \\ University of Wollongong \\ Wollongong, NSW, Australia \\ tomgold@uow.edu.au
}

\author{
Mark J. W. Lee \\ School of Education and RIPPLE \\ Charles Sturt University \\ Wagga Wagga, NSW, Australia \\ malee@csu.edu.au \\ Christian H. Ritz \\ Engineering and Information Sciences \\ University of Wollongong \\ Wollongong, NSW, Australia \\ crtiz@uow.edu.au
}

\begin{abstract}
A key goal of engineering education is to ensure students are adequately prepared to enter professional practice. Unfortunately, students have been found to bring to university significant misconceptions about the types of work engineers perform, which can have an adverse impact on their readiness to fully appreciate and benefit from course activities. This paper presents a case study of how iSee, a collaborative online platform that allows for video conferencing within a three-dimensional immersive virtual world, was used to host a careers fair event in which students learned about the engineering profession and about the various engineering majors available to them by networking and interacting with alumni and faculty. The planning and execution of the event are described, along with the pedagogical, technological, and logistical considerations and design decisions that were made. Preliminary results suggest the activity, despite being low cost, was effective at generating productive dialogue between participants that focused on what students could expect upon graduating in terms of employment prospects, as well as the academic pathways and other learning opportunities they needed to pursue to realize their goals.
\end{abstract}

Keywords - career guidance, choice of major, compitersupported collaborative learning, engineering profession, industry engagement, video conferencing, virtual world.

\section{INTRODUCTION}

Engineering is a practically oriented profession, and the ultimate purpose of engineering education is to equip students with the knowledge, skills, and attributes they need to tackle real-world problems of relevance to society and for the advancement of humankind [1], [2]. The teaching laboratory plays an important part in preparing students for professional practice, and a body of research has looked at how engineering laboratory experiences can be improved and enhanced to facilitate more authentic, professionally relevant learning for students [3]-[6]. However, laboratory work alone is insufficient for ensuring students develop the practical skills and dispositions demanded by industry. Research studies and reports have stressed the importance of bridging the gap between university and the workplace, and of developing in engineering students the generic skills and attributes necessary to operate successfully on the job [7]-[9]. Additionally, it has been found that students come to higher education institutions poorly informed or misinformed about the role of an engineer and the work he/she actually carries out [1], which may prevent them from fully appreciating the value of, and actively engaging with, many of the learning opportunities with which they are presented in their courses.

Careers fairs are a useful way of affording students exposure to industry and helping them gain knowledge about the profession. Career fairs benefit students by enabling them to develop broader and deeper awareness of relevant career options, to understand hiring processes and internships, and to develop relationships with industry professionals and potential future employers [11]-[13]. This paper reports on a trial of an innovative approach to running a careers fair targeted at firstyear undergraduate and postgraduate coursework engineering students across a range of engineering disciplines at a regional Australian university. A hybrid video conferencing and threedimensional (3D) virtual world platform was used to host the fair to mitigate time and distance barriers. The desired criteria for the virtual careers fair included being low cost, simple to plan and execute, and attractive for students to participate.

\section{CASE BACKGROUND}

In 2015, the University of Wollongong (UOW) moved to a common first-year undergraduate structure across all of the 
nine engineering disciplines offered by its three schools of engineering, namely the School of Civil, Environmental, and Mining Engineering; School of Electrical, Computer, and Telecommunications Engineering; and School of Mechanical, Materials and Mechatronics Engineering. This was done in order to give students the flexibility to either select their intended major at the time of entry to the program (with the ability to change their preference at a later stage) or to defer the selection until second year. The premise for the move was that students have greater awareness and understanding of their interests after completing their first year of study, at which point they are better placed to make an informed choice in this regard.

During the transition to the engineering common first-year (ECFY) model, anecdotal feedback from and conversations with first-year students indicated that many had significant false impressions and misunderstandings about what an engineering degree entails, and of the types of opportunities that await them upon graduation. Many also commented that they found it difficult to commit to a particular field of specialization purely on the basis of the limited exposure they received in the core courses that made up the ECFY. The faculty saw a burning need to help students become better informed in order to assist their choice of major, and indeed to obtain greater insight in terms of whether an engineering career was something they wished to pursue.

At the same time, a more common postgraduate engineering coursework program (non-research degrees, also known as postgraduate taught degrees) has commenced across the University's three engineering schools. The vast majority of students in this program are international students with little or no work experience in Australia. To help both the undergraduate and postgraduate coursework students an online career fair was proposed with alumni being used to motivate and provide perspective from their experience in their discipline. This approach would also provide a learning opportunity to practice oral communication skills with industry. An online approach was selected to encourage participation by alumni from around the world, as local job opportunities around the university are limited.

\section{TECHNOLOGY OPTIONS}

A number of synchronous online collaboration technologies and platforms were deliberated as possible options for facilitating the virtual careers fair. However, the strengths and weaknesses of the technologies needed to be considered in order to select the most suitable. Standard two-dimensional (2D) technologies such as Skype, Google Hangouts and Adobe Connect were ruled out due to scalability issues as these technologies struggle with participants that significantly exceed ten [13].

An alternative is 3D technologies such as Second Life and OpenSim that are scalable, flexible, allow freedom of movement within a virtual world but are restricted due to their animated avatars limiting facial and body language cues [14]17]. An immersive video augmented alternative is iSee [18]. This technology uses personal video-based avatars (see Figure 3 ) that move freely in a virtual world using spatial sound and limited bandwidth [19], [20], allowing for the replication of a career fair. In a recent study also conducted by the authors of the present article [22], third-year undergraduate students in an project-based engineering design course with industry guests to solicit advice and feedback on their early product design concepts. The study was the first of its kind and involved a limited number of users. The experience from that study provided the authors with the confidence and inspiration to attempt to use the same technology to run an event that could potentially include a massive number of participants, and gave them a reference point and knowledge base from which to draw when making decisions with respect to the design of the virtual environment and activity.

\section{PLANNING AND EXECUTION}

\section{A. Student Invitations}

All 450 undergraduate students enrolled in the ECFY in 2015 were invited to participate in the virtual careers fair. The authors believed that the event would be seen by the students as extremely valuable, and for this reason opted to make participation voluntary and non-assessable. The first author conducted a presentation in one of the common first-year courses. The presentation provided an overview of the iSee program, the reasons why the technology was chosen, details about the online career fair and the learning opportunities available through participation. Prior to the event, students were reminded about the fair during the tutorial classes of another first-year course. The event was also promoted on social networks including Facebook and Twitter.

All postgraduate coursework students enrolled in a core research design course were also invited to attend the event. This course has a major assessment component that focuses on oral communication skills; participation would not only provide students with valuable exposure to Australian industry but would also complement their learning in the course by providing valuable communication practice. As was the case with the undergraduate students, participation in the virtual careers fair was voluntary for the 138 postgraduate coursework students. However, the possibility of earning up to four bonus marks was used to encourage participation, with the number of marks awarded to be determined based on the percentage of students participating. The event was advertised to the postgraduate coursework students simply by way of an email to all those enrolled in the cohort.

\section{B. Logistics}

The advantage of the online event was that members from industry could participate from throughout the world, allowing for a diverse range of occupations to be present. For example, we had an alumnus from Facebook in the United States 
participate. As a result, the organization of the event did not require the booking and associated costs of hall hire, accommodation, travel, catering, security, and parking. The logistics of the event itself were simple in that participants only needed access to an Internet-enabled computer, a webcam, and a microphone. All they needed to do in preparation for the event was to download, install, and test the software. Predefined, supported testing times were arranged for troubleshooting purposes, which only a minority of participants took advantage of. Documents explaining the event, technology, and requirements were distributed. The event was held at 7:00 pm to allow industry guests to participate after work and to limit timetable clashes for students (university classes run between 8:30 am and 8:30 pm on weekdays).

The bulk of the workload for the organizers was in finding alumni prepared to participate in the career fair. This task was led by the first author of the present article, who was employed in a faculty-wide engineering education role but had been involved in teaching students within the electrical, computer, mechatronics, and telecommunications disciplines. The first author had, over the years, amassed a large database of alumni who were connected to his LinkedIn profile, and he was able to use this as a starting point for locating potential guests who he believed would be of interest to students. Across the four disciplines, 23 alumni were invited, with nine accepting, four declining due to prior scheduled commitments, and ten not responding at all.

As the first author did not have connections within the other five disciplines, a list of alumni was obtained from university administration together with recommendations solicited from the two heads of school. Using contact details from this list, three materials engineering alumni were invited, all three of whom agreed to participate. Securing participation from civil, mechanical, environmental, and mining engineering alumni, however, proved extremely difficult. Across the four disciplines, 45 invitations were extended, with only one environmental alumnus and one mechanical alumnus accepting. Possible causes of this include the individuals having no major connection to the first author, the value they placed on their undergraduate experience, or a general lack of comfort in using technology.

As part of the recruitment process, invitees were notified of the research nature of the event. Participant information sheets were supplied and all instructions outlined important research information, including that the event would be recorded for later playback and analysis. This may have been a disincentive for some to participate.

\section{Event Venue Layout}

A total of 180 participants registered for the virtual careers fair, excluding the alumni and research team. In order to accommodate such a large number of video avatars, the virtual environment was segmented into four separate spaces, as shown in Figure 1. This comprised of three grand halls for presentations, plus an outdoor gathering area. The segmentation of the environment was to ensure that there was space for conversations to take place without excessive noise or overcrowding, and to better accommodate participants with less capable computer and graphics processors by reducing the number of video avatars needing to be rendered [21].

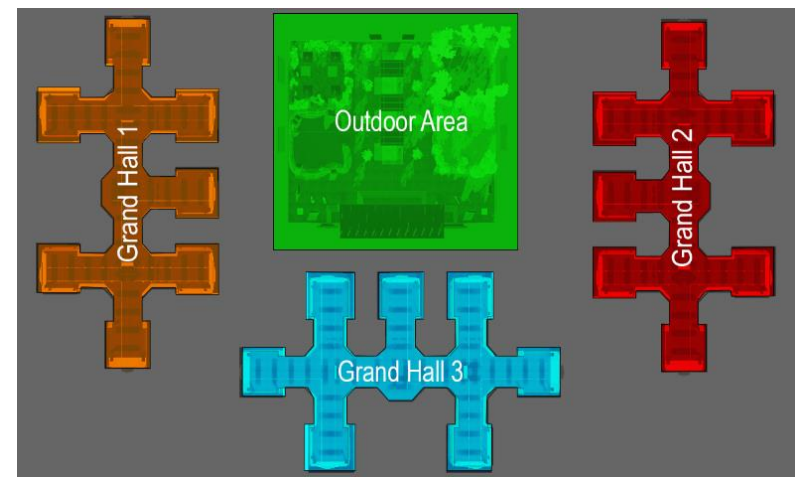

Figure 1. Map of the virtual world venue used for the career fair.

Each alumnus was allocated a presentation zone consisting of an interactive board preconfigured to display their profile information, an example of which is shown in Figure 2. Each grand hall contained seven presentation zones, the original intention being that each of the three schools of engineering would have a dedicated grand hall, with six zones having alumni from the relevant school and the remaining zone serving as a technical helpdesk. Unfortunately, as previously outlined, some schools had limited alumni representation. In the end, two of the halls had five presenting alumni and a helpdesk in it, while the third hall had four alumni, a helpdesk, and a representative from the IEEE Student Branch. Figure 3 is a snapshot of the outdoor area, which, in addition to being a space for participants to mingle and socialize, was also used to deliver the closing speech.

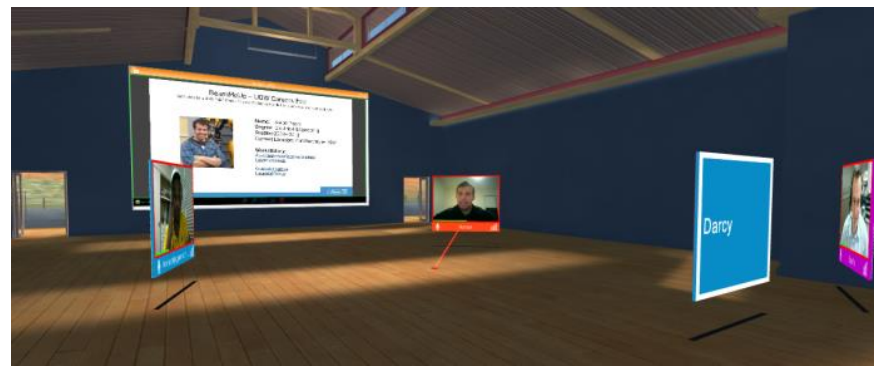

Figure 2. An example of a presentation zone with a display board, presenting alumnus, and students

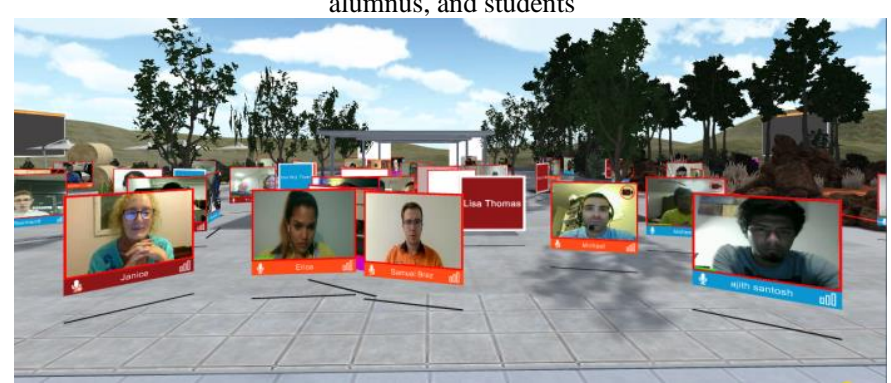

Figure 3 . The outdoor area in use by 72 video avatars 


\section{RESULTS AND DISCUSSION}

\section{A. Event Participation}

From the 180 registrations, only 89 individuals participated in the virtual careers fair, the breakdown of which was as follows: 14 first-year undergraduate students (3\% participation rate), 1 second year student (as a result of social media advertising), 14 alumni, 19 academic guests from Wollongong and around Australia, 31 postgraduate students (23\% participation rate), and 10 involved with running the event. At the conclusion of the event, participants were sent a request to fill out anonymous online survey to help understand what they thought about the experience.

With a quarter of all first-year undergraduate students having yet to select a major, a greater participation rate than $3 \%$ was expected from the first-year students. A total of 14 first-year student responses were received for the online survey. Reasons for their participation in the event are outlined in Table I, and are concentrated on bonus marks, understanding career choices and interest in the iSee technology. Interestingly, no bonus marks were provided to first year students for participation. All of the students agreed that it was a beneficial learning experience and would be happy to participate in an event like this again. When asked for their views on why other students did not participate, comments could be grouped between "no interest" and "too many assessments due."

The postgraduate students were encouraged to participate in the event based on a bonus mark determined by the percentage of students in the course that attended. Of the 31 postgraduate students that participated in the event, 17 completed the online survey; their aggregate responses to the question on reasons for participating are summarized in Table II. Their responses to this question displayed more variation than those of the undergraduate students $(S D$ for postgraduate $=16.53 ; S D$ for undergraduate $=22.77$ ), but were heavily concentrated toward the bonus marks that were on offer.

All students indicated that they would be happy to participate in a similar event again, with $95 \%$ expressing a view that it was a beneficial learning experience. When asked why other students did not participate, most answers suggested that those students had "ignored information advertising the event."

The difference in participation between the two approaches is very noticeable. The first year students were heavily sold on the benefits of interacting with industry for their studies, understanding of engineering and career development. However, the lack of grades and pressures from other activities resulted in only the most interested students participating. The postgraduate students received a minimal amount of advertising but the promise of bonus marks was clearly shown to be a contributing factor to the higher participation rate. These students were also much more interested in working with a specific company but far less interested in understanding career choice. This may be seen as reflective of the differences in career stages between the undergraduate and postgraduate students.

TABLE I

FIRST-YEAR UNDERGRADUATE STUDENT REASONS FOR PARTICIPATING IN THE VIRTUAL CAREERS FAIR

\begin{tabular}{lc}
\hline \hline \multicolumn{1}{c}{ RESPONSE } & PERCENTAGE \\
\hline Bonus marks & $50 \%$ \\
Help with degree choice & $29 \%$ \\
Understand career choices & $50 \%$ \\
Network & $29 \%$ \\
Scholarship or work experience opportunities & $29 \%$ \\
Find out more about working in a specific company & $15 \%$ \\
Interested in the iSee technology & $50 \%$ \\
Other (please specify) & $7 \%$ \\
\hline \hline
\end{tabular}

Note: Students were asked to select all responses applying to them.

TABLE II

PostgraduAte StUdENT REASONS FOR PARTICIPATING IN THE VIRTUAL CAREERS FAIR

\begin{tabular}{lc}
\hline \hline \multicolumn{1}{c}{ RESPONSE } & PERCENTAGE \\
\hline Bonus marks & $76 \%$ \\
Help with degree choice & $12 \%$ \\
Understand career choices & $35 \%$ \\
Network & $35 \%$ \\
Scholarship or work experience opportunities & $24 \%$ \\
Find out more about working in a specific company & $42 \%$ \\
Interested in the iSee technology & $42 \%$ \\
Other (please specify) & $0 \%$ \\
\hline \hline
\end{tabular}

Note: Students were asked to select all responses applying to them.

\section{B. Industry Perspective}

A total of 10 of the 14 alumni presenting to the students completed the online survey. The major reasons for participating were due to having a desire to give back to the university (100\%) and being eager to meet the students $(50 \%)$. All alumni indicated that they would be happy to participate in a similar event again, with $90 \%$ indicating that they believed it was a beneficial learning experience, and $70 \%$ wishing that they had been given this type of opportunity as a student

\section{Observations}

A powerful feature of the iSee platform is the ability to capture a full 3D recording of the environment, allowing every conversation and interaction to be reviewed in retrospect. (This creates large data files - a 15-minute recording across the four segments of the virtual environment used for the careers fair equated to a file of approximately one gigabyte in size.) Each recording would need to be watched repeatedly to observe different conversations occurring at the same time. For this one-hour event, ten hours was spent reviewing the footage, yet many conversations were still missed. Work is needed to develop a more systematic and reliable method of analyzing this type of data.

One of the goals of this innovative approach was to encourage social interaction and networking. The authors believe this was successfully accomplished, but one major flaw was observed: with the event having attracted 180 registrations, the virtual world had been designed to be large and spacious enough to facilitate robust audio and video 
communication, with minimal interference/noise from other, nearby users. However, with the number of participants being half of what was expected, the a grand halls felt at times more like a ghost town then a career fair. The excessive space meant that some alumni were left waiting for as long as 10 to 15 minutes without any visitors to their presentation zones. At times the alumni left their posts and initiated causal conversations with one another; this mirrors what would likely happen in a physical career fair if the number of stalls exceeded student demand.

Some of the participants sought out discussions with the alumni individually. Many of these students gained valuable communication practice. This is because some where very shy or really lacked the confidence to undertake small talk. In these situations, to the credit of the alumni, they would push along the conversation and increase student engagement. Some of the conversation was targeted at university and jobs and some on small talk, leading to great communication competency.

Many of the participants were most comfortable in a group conversation. As some alumni had an empty presentation zone, others were at times surrounded by five or six avatars as shown in Figure 4. This congregation of video avatars (in relation to the total number of participants) contributed to the ghost town feeling in other parts of the hall. The ability to travel through the virtual world, see a group conversation and join with ease are true advantages of platforms like Second Life and iSee, with iSee taking that advantage further in allowing for a person's face and body language to be seen.

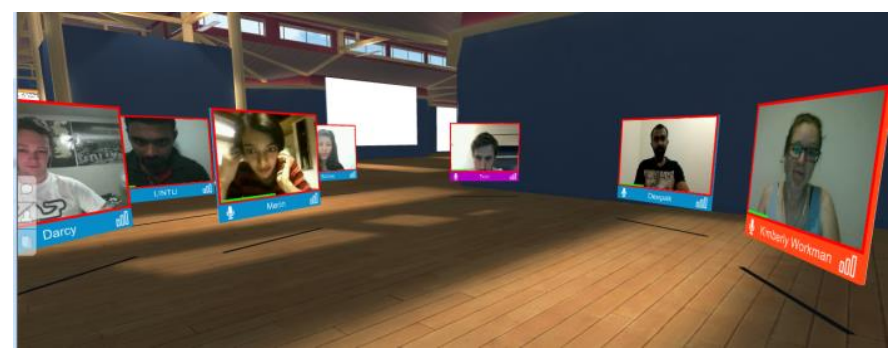

Figure 4. An example of a group conversation in iSee

Surprisingly, the academic guests did not seem to spend a considerable amount of time interacting with the students or alumni. They mainly wandered around the virtual world exploring the technology, and then congregated in groups in the corridors of the grand halls talking about the usefulness of the technology. Some of the students also congregated in the corridors. It appeared that some of these students could not find enough alumni to speak to, as some disciplines only one or less representatives, and they didn't want to find value in speaking to alumni from other disciplines. On the other hand, some postgraduate students appeared less engaged and primarily motivated by spending time on the activity to qualify for bonus marks.

The students that appreciated the full potential of the careers fair benefited greatly. Interactions with the alumni in many cases targeted many of the engineering misconceptions. Typical student questions included: "What do you actually work on during the day?" and "Can you provide examples of projects you are working on?" Other conversations focused on jobs and networking, such as "When you left uni, did employers concentrate on your marks or experience?" and "What do you look for when you hire someone?" Many of these conversations led the alumni to explain what the students should expect out of the university in terms of learning. Some related their professional experience back to specific courses that the students will experience in their degree.

Within the event most of the participants portrayed the image that they were enjoying themselves. The ability to see people smiling and laughing (apart from simply hearing) is what contrasts the difference between iSee and Second Life. Facial expressions and body language play a large role in successful communication. Students in particular had fun testing the capabilities such as jumping up and down and racing their video avatar through the virtual halls.

The final activity of the event was to test the capability of the iSee platform with large numbers of video avatars. At the conclusion of the career fair all participants were asked to teleport to the outdoor virtual world for the test. A total of 72 video avatars were located in one open space as was shown in Figure 3. Virtual worlds place a heavy load on CPU, GPU, and memory resources [21], and this load significantly increased when 72 participants co-located in the one area. As was expected, participants with low end computers struggled to process the required data, while participants with high end computers noticed no difference in their user experience. Network performance did not play an important role due to the algorithms used by the iSee platform [21], [22].

The end of formalities led to free time for participants to network. Within the open space, approximately ten different group conversations occurred simultaneously, the number changed as participants moved around. Groups generally consisted of: alumni and students when the students had more questions to ask; alumni interacting with alumni; students interacting with other students; and the organizers (research team) undergoing a debriefing. Of especial interest was the fact that about one quarter of the student participants remained in the iSee environment for up to an hour talking to one other about university and social manners. A video containing snippets of the event is available for viewing at [23].

\section{LOGISITICAL CONSIDERATIONS}

A number of design decisions were made on the basis of lessoned learned from an earlier study [22]. The first was based on design of the virtual environment. As three separate grand halls were used to house the alumni presentations, it was important to ensure participants were evenly split across each. To achieve this, instructions were sent to participants directing them to one of the three halls based on the first letter of their surname. While most followed the instructions, as in the 
earlier study the third hall was the least utilized. In an ideal scenario, the use of a single grand hall would be best, but considering that 180 registered for the event, employing a single contiguous space would likely have resulted in a negative experience for participants with low computer specifications.

Training was also identified as being crucial for success. While multiple testing and training opportunities were provided, most were not taken advantage of. This was anticipated by the organizers and led to the allocation of a helpdesk within each grand hall. Many participants arrived confused about where they should go or what they should do, and this service was very beneficial.

Identifying different users is very important. In a virtual environment it can be hard to identify the type of participant. To address this, color coded avatars were used. Presenting alumni were represented by orange, students with blue, guests as red and research team in purple. This worked successfully as participants could easily identify if other participants were a student, guest, presenting alumni or part of the research team.

\section{CONCLUSION}

The purpose of this case study was to build upon existing practice in virtual world literature to run a manageable, low cost career fair suitable for first year undergraduate and postgraduate students. This approach differs from other virtual world related technologies due to the video avatar approach. The approach worked reasonably well with great engagement between the students and presenting alumni, which appeared to help alleviate some of the misconceptions students associate with engineering. It also provided a comfortable environment for students to practice communication and networking skills with industry. Similar activities like this could help engineering students and faculty develop stronger relationships with industry.

The workload and cost of running the event was minimal considering the cost of running a real career fair. Using the technology, alumni from around Australia and the world were able to participate with no cost. The greatest workload came in trying to find some alumni to represent a number of the engineering disciplines such as civil, environmental mechanical and mining engineering. Further work needs to consider the barriers to participation for the four disciplines.

The major negative of the event was the percentage of students that participated. While the benefits of participation were repetitively advertised to students, the lack of assessment resulted in a poor participation rate. This contrasts to the postgraduate students that had little advertisement with bonus marks resulting in higher participation. This highlights that work needs to be carried out on how to change students from being simply assessment driven.

\section{REFERENCES}

[1] J. Trevelyan, The Making of an Expert Engineer. London, UK: CRC Press/Balkema, 2014.
[2] S. P. Nichols, "Professional responsibility: The role of the engineer in society," Sci. Eng. Ethics, vol. 3, no. 3, pp. 327-337, 1997.

[3] L. D. Feisel and A. J. Rosa, "The role of the laboratory in undergraduate engineering education," J. Eng. Educ., vol. 94, pp. 121-130, 2005.

[4] S. Nikolic, C. Ritz, P. J. Vial, M. Ros, and D. Stirling, "Decoding student satisfaction: How to manage and improve the laboratory experience," IEEE Trans. Educ., vol. 58, pp. 151-158, 2015.

[5] S. Nikolic, P. J. Vial, M. Ros, D. Stirling, and C. Ritz, "Improving the Laboratory Learning Experience: A Process to Train and Manage Teaching Assistants," IEEE Trans. Educ., vol. 58, pp. 130-139, 2015

[6] S. Nikolic, "Training laboratory: Using online resources to enhance the laboratory learning experience," in IEEE Int. Conf. Teaching, Assessment and Learning for Engineering, 2014, pp. 51-54.

[7] D. Edwards, K. Perkins, J. Pearce, and J. Hong, Work Integrated Learning in STEM in Australian Universities. Office of Chief Scientist \& Australian Council for Educational Research, Canberra, ACT, Australia, 2015.

[8] S. Male and R. King, "Best practice guidelines for effective industry engagement in Australian engineering degrees," Australian Council of Engineering Deans, Brisbane, Qld., Australia, Jun. 2014.

[9] E. Berjano, L. Sales-Nebot, and A. Lozano-Nieto, "Improving professionalism in the engineering curriculum through a novel use of oral presentations," Eur. J. Eng. Educ., vol. 38, pp. 121-130, 2013.

[10] J. Trevelyan, The Making of an Expert Engineer. London, UK: CRC Press/Balkema, 2014.

[11] B. K. Payne and M. Sumter, "College students' perceptions about career fairs: What they like, what they gain, and what they want to see," College Student J., vol. 39, p. 269, 2005.

[12] A. Milman and P. A. Whitney, "Evaluating students' experience and satisfaction at a hospitality and tourism college career fair," J. Human Resources Hospitality Tourism, vol. 13, pp. 173-189, 2014.

[13] C. Brennan, M. Daly, E. Fitzpatrick, \& E. Sweeney, "Tradition versus technology: Careers fairs in the 21st century," Int. J. Educ. Vocational Guidance, vol. 4, no. 1, pp. 23-41, 2004.

[14] J. C. Tang, C. Wei, and R. Kawal, "Social telepresence bakeoff: Skype group video calling, Google+ Hangouts, and Microsoft Avatar Kinect," in Proceedings of the ACM 2012 Conf. Comp. Supported Coop. Work Companion, 2012, pp. 37-40.

[15] B. Dalgarno and M. J. W. Lee, "What are the learning affordances of 3D virtual environments?," Brit. J. Educ. Technol., vol. 41, pp. 10-32, 2010.

[16] S. Gregory, L. Jacka, M. Hillier, and S. Grant, "Using virtual worlds in rural and regional educational institutions," Australian Int. J. Rural Educ., vol. 25, pp. 73-90, 2015.

[17] S. Nikolic, M. J. W. Lee, and P. J. Vial, "2D versus 3D collaborative online spaces for student team meetings: comparing a web conferencing environment and a video-augmented virtual world," in Proc. 26th Annual Conference of the Australasian Association for Engineering Education, Geelong, 2015.

[18] C. X. Wang, S. Anstadt, J. Goldman, and M. L. M, "Facilitating Group Discussions in Second Life," MERLOT J. Online Learn. Teaching, vol. 10, pp. 139-n/a, Mar. 2014.

[19] iSee Meetings. (2015). Available: http://www.isee-meetings.com/

[20] F. Safaei, P. Pourashraf, and D. Franklin, "Large-scale immersive video conferencing by altering video quality and distribution based on the virtual context," IEEE Commun. Mag, vol. 52, pp. 66-72, 2014.

[21] P. Pourashraf, F. Safaei, and D. R. Franklin, "Minimisation of video downstream bit rate for large scale immersive video conferencing by utilising the perceptual variations of quality," in IEEE Int. Conf. Multimedia and Expo., 2014, pp. 1-6.

[22] M. J. W. Lee, S. Nikolic, P. J. Vial, C. Ritz, W. Li, and T. Goldfinch, "Enhancing project-based learning through student and industry engagement in a video-augmented 3D virtual trade fair," IEEE Trans. Educ., in press.

[23] SECTEUOW. (2015). Virtual Worlds Using a Video Avatar - Exploring a Virtual Careers Fair [Video file]. Available: https://www.youtube.com/watch?v=QSCpmNuZAWE 